\title{
Characterization of the Interface Between $\alpha$ and $\beta$ Titanium Alloys in the Diffusion Couple
}

\author{
MACIEJ MOTYKA, WOJCIECH J. NOWAK, BARTEK WIERZBA, \\ and WITOLD CHROMINSKI
}

The aim of the research was to investigate the microstructural changes caused by diffusion through interface between $\alpha$ and $\beta$ titanium solid solutions. For this purpose, a diffusion couple composed of two single-phase titanium alloys - $\alpha$ type commercially pure (CP) titanium Grade 2 and near- $\beta$ Ti-15V-3Al-3Cr-3Sn — was made by annealing at a temperature of $850{ }^{\circ} \mathrm{C}$ in an inert atmosphere. The performed heat treatment caused partial diffusion bonding (DB) where the $\alpha /$ $\beta$-interface was clearly visible. Based on the results of microscopic (light microscope (LM), scanning electron microscope/electron backscatter diffraction (SEM/EBSD), and transmission electron microscope (TEM)) examination, a significant microstructure evolution of near- $\beta$ alloy in the region near the interface (diffusion-affected zone) was revealed. It was found that needlelike phases were formed both in $\alpha$ and $\beta$ solid solutions. Moreover, in the near- $\beta$ titanium alloy, pores aligned in the Frenkel plane were found. The latter finding indicated that the diffusion of alloying elements of near- $\beta$ alloy is the most probable reason for the observed microstructural changes. Additionally, the "grooving" phenomenon at the $\alpha / \beta$ interface was found and it was correlated with faster diffusion through grain boundaries, rather than volume diffusion. Finally, the pore size was measured and numerically modeled. The calculated values were in good agreement with the experimental ones.

https://doi.org/10.1007/s11661-020-06023-5

(C) The Author(s) 2020

\section{INTRODUCTION}

TITANIUM and its alloys are widely used in almost all sectors of human life, e.g., in production of medical pacemakers, hydraulic tubing, engine parts, automotive parts, various sports equipment such as golf clubs, aircraft turbines, and structural honeycomb components or fasteners used in aerospace. Titanium at the temperature below $882{ }^{\circ} \mathrm{C}$ exhibits hexagonal-close-packed (hcp) crystal structure with suitable adjustments of the lattice structure and bond strength depending on alloying, generally called $\alpha$ alloys. $^{[1]}$ The most popular single-phase $\alpha$-Ti is commercially pure (CP) titanium, which is, in fact, a Ti-O alloy. The hardening of this alloy is done by adding a controlled amount of oxygen, which dissolves interstitially in the metal. However, when heating above $882{ }^{\circ} \mathrm{C}$, a phase transformation occurs and the body-centered-cubic (bcc) structure is

MACIEJ MOTYKA, WOJCIECH J. NOWAK, and BARTEK WIERZBA are with the Department of Materials Science, Faculty of Mechanical Engineering and Aeronautics, Rzeszow University of Technology, Al. Powstancow Warszawy 12, 35-959 Rzeszow, Poland. Contact e-mail: motyka@prz.edu.pl WITOLD CHROMINSKI is with the Faculty of Materials Engineering, Warsaw University of Technology, ul. Woloska 141, 02-507 Warszawa, Poland.

Manuscript submitted March 19, 2020. Accepted 6 September 2020.

Article published online October 16, 2020 stable and it is referred to as the $\beta$ phase. To stabilize the $\alpha$-Ti phase, most commonly $\mathrm{Al}$ is added into the alloy, while for $\beta$-Ti stabilization, $\mathrm{V}$ or Mo is introduced. The mechanical properties of both phases differ, namely, the $\beta$ phase possesses higher strengths after aging, it deforms easier, and it exhibits much higher diffusivity for interstitial elements. However, $\beta$ alloys are characterized by lower creep resistance, higher density, and greater expense. ${ }^{[2]}$

Microstructure development of two-phase $(\alpha+\beta)$ titanium alloys plays a crucial role in achieving their required properties. It is usually realized in thermomechanical processes (including heat treatment and hot deformation operations) leading to microstructure evolution based on the effects of $\alpha+\beta \leftrightarrow \beta$ and $\beta \rightarrow \alpha^{\prime}\left(\alpha^{\prime \prime}\right)$ phase transformations. ${ }^{[3]}$ Other important mechanisms are based on interactions between $\alpha$ and $\beta$ crystals, causing fragmentation and spheroidization of $\alpha$ grains during hot deformation processes. ${ }^{[4,5]}$ It is generally accepted that spheroidization of $\alpha$ grains (lamellae) through their fragmentation is caused by the pile up of dislocations leading to shearing and rotation of grains. Formation of low-angle and subsequently high-angle boundaries in the smallest cross section of $\alpha$ lamellae causes their partition and spheroidization. ${ }^{[6,7]}$ Boundary splitting during the fragmentation of $\alpha$ lamellae is related to the thermal "grooving" process. Based on 
the classical model of such a process, proposed by Mullins, ${ }^{[8]}$ the grain growth of one phase $(\beta)$ into the interface $(\alpha / \beta)$ causes grain boundary formation $(\alpha / \alpha)$ in the adjacent grain of the second phase $(\alpha)$.

Spheroidization of $\alpha$ phase grains in titanium alloys has been studied extensively in various aspects. ${ }^{[9-12]}$ Such process results from fragmentation of the elongated grains for which the "grooving" formation decreases the surface tension of the grain boundary. ${ }^{[8,12]}$ According to Semiatin and Pilchak, ${ }^{[13]}$ the fragmentation of $\alpha$ lamellae ("platelet fragmentation") during hot working and the early stages of annealing of hot working is a process dominated by spheroidization behavior. They also suggest that the sub-boundaries laying normal to the $\alpha / \beta$ interface enable grooving resulting in full penetration across the thickness of $\alpha$ lamella. While the fragmentation of $\alpha$ lamellae leading to their spheroidization is quite extensively described in the literature, the grooving of $\beta$ phase crystals has not been reported. It can be assumed, on the basis of theoretical analysis, ${ }^{[14,15]}$ that the grooving direction depends rather on the geometry of interface (e.g., grain boundary inclination angle) and crystal defects in both separated phases (Figure 1).

The thermal grooving process requires transport of mass from the curved interfaces at the groove area to the flat interfaces of the same or adjacent $\alpha$ lamella. ${ }^{[16]}$ The diffusion through the $\alpha / \beta$ interface seems to be a very important process for the microstructure development in titanium alloys. It is not comprehensively described in the published research data, probably due to difficulties in experimental analysis of microzones of $\alpha+\beta$ titanium alloys. Very few attempts ${ }^{[17]}$ were made to evaluate the interdiffusion between dissimilar titanium alloys, but they did not apply to single-phase materials. Therefore, the idea of the research described in this article was to study the diffusional process between $\alpha$ and $\beta$ phases. The alpha titanium allotropic form (hcp) is stable below $882.5^{\circ} \mathrm{C}$; therefore, $\mathrm{CP}$ titanium was selected as a single $\alpha$ phase material, whereas due to the instability of beta titanium (bcc) at room temperature, $\beta$-type titanium alloy was used in the examined diffusional couple.

During the diffusion process between dissimilar metallic materials, numerous phenomena can occur due to the differences in diffusion coefficients. Stresses can be generated ${ }^{[18-22]}$ and the Kirkendall-Frenkel effect causes the void formation. The voiding is a result of relaxation in pure metal or an alloy supersaturated with

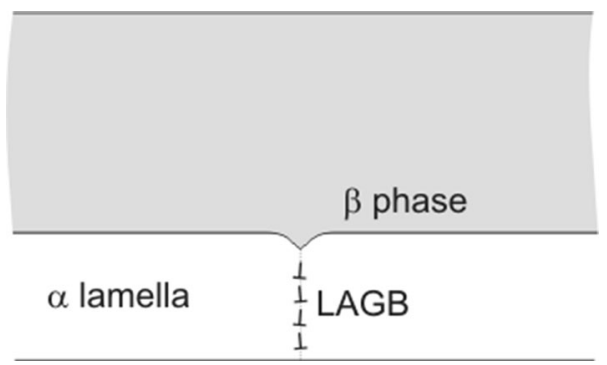

Fig. 1-Schematic of $\beta$ phase grain growth by grooving of the $\alpha / \beta$ interphase (LAGB - low-angle grain boundary). vacancies. The relaxation of vacancy subsystem can proceed by the vacancies merging into voids. ${ }^{[23-25]}$ Despite the fact that voiding does not occur during the diffusion process through $\alpha / \beta$ interfaces in two-phase titanium alloys, such phenomenon was observed and analyzed in the article for the diffusion pair of dissimilar alloys. Most articles on the diffusion process through interface concern the couples composed of different elements. ${ }^{[21,22,25-28]}$ Diffusional interaction between titanium alloys is usually analyzed from the aspect of diffusion bonding (DB) technology of the same alloys ${ }^{[29]}$ or dissimilar ones. ${ }^{[30-33]}$

Since the two-phase $\alpha+\beta$ titanium alloys were widely studied at high temperature and described, ${ }^{[4-15]}$ almost no work deals with the diffusion process between the two phases of Ti, namely, $\alpha$-Ti and $\beta$-Ti. The volume diffusion through the $\alpha / \beta$ interface seems to be a very important process for the microstructure development in titanium alloys. It is not comprehensively described in the literature, probably due to difficulties in its experimental analysis of microzones of $\alpha+\beta$ titanium alloys. Therefore, the idea of the research described in this article was to study the phenomena occurring during the diffusion process between $\alpha$ - and $\beta$-Ti alloys. Such preliminary research will be the basis for further investigations on mass transfer between different phases in titanium alloys. Even the analyzed interface is formed between dissimilar alloys. The presented data could be useful for selection of the DB process conditions as well.

\section{MATERIALS AND METHODS}

The sheets of Grade 2 CP titanium ( $\mathrm{Ti} \geq 98.9$ wt pct) and Ti-15V-3Al-3Cr-3Sn (chemical composition given in wt pct) near- $\beta$ alloy having the thickness of $0.7 \mathrm{~mm}$ were used. For the case of simplicity, the CP titanium will be further designated as $\alpha-\mathrm{Ti}$ and Ti-15V-3Al-3Cr-3Sn alloy as $\beta$-Ti. Plates of $15 \times 15 \mathrm{~mm}^{2}$ were cut from both sheets, ground, and polished to mirror finish using $\mathrm{SiC}$ papers and diamond pastes down to $0.25-\mu \mathrm{m}$ particle size. The plates, after ultrasonic cleaning, were connected in a molybdenum holder to form the diffusion couple. Annealing was conducted in a tube furnace in an inert argon atmosphere (5 purity) at $850{ }^{\circ} \mathrm{C}$ (below the temperature of alpha $\leftrightarrow$ beta allotropic transformation) for 24 hours. The sample was placed in a glass tube, closed, and flushed with argon for 2 hours to remove the remaining air and prevent oxidation of the investigated diffusion couple. During flushing, the sample was placed outside the hot zone of the furnace. After the flushing stage, the furnace was heated to test temperature and then the sample was put into the hot zone of the furnace and kept for a given time at a constant temperature. At the end of the exposure time, the sample was moved from the tube outside the furnace hot zone and cooled to room temperature. After annealing, the diffusion couple was mounted in bakelite. A metallographic cross section was prepared according to the standard procedure. The microstructure observations and the void radius measurements were carried out using a Leica DM3000 light microscope (LM). Additionally, scanning electron 

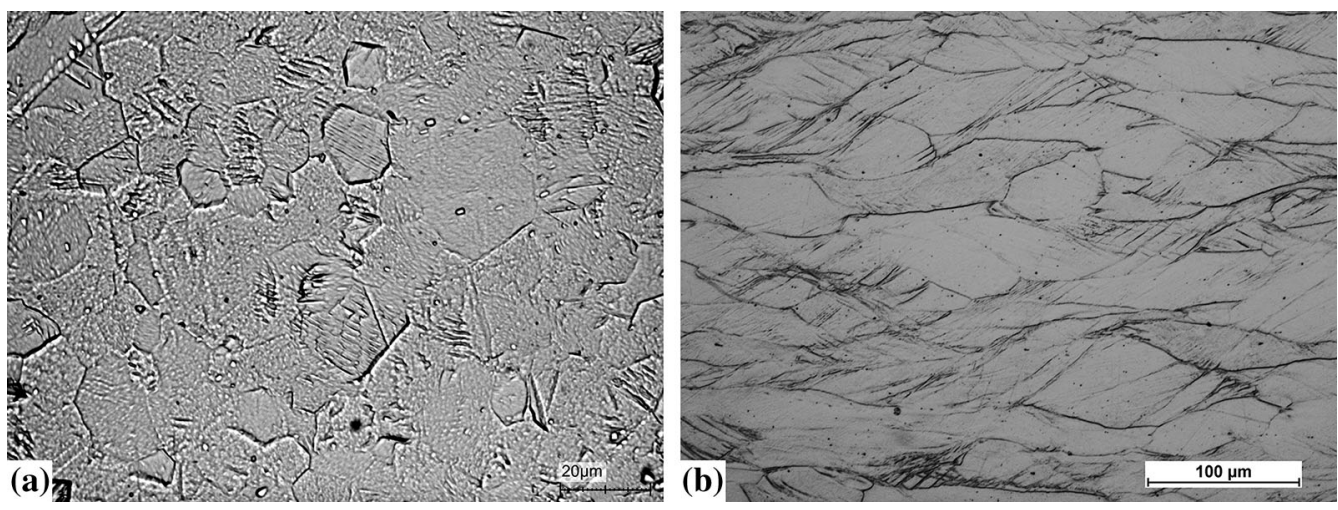

Fig. 2-Microstructure (LM-longitudinal cross section) of as-received titanium alloys: (a) $\alpha$-Ti (Grade 2) and (b) $\beta$-Ti (Ti-15V-3Al-3Cr-3Sn).

microscope (SEM) and energy dispersive spectrometry (EDS) analyses were performed using a Hitachi S-3400N apparatus.

Specimens for transmission electron microscope (TEM) observations were prepared with conventional electropolishing of $3-\mathrm{mm}$ discs. The bath contained perchloric acid and methanol in the 1:4 ratio. TEM experiments were carried out with a JEOL* JEM 1200

*JEOL is a trademark of Japan Electron Optics Ltd., Tokyo.

EX II operated at $120 \mathrm{kV}$.

Electron backscatter diffraction (EBSD) was done with the use of a Hitachi SU70 FEG microscope operated at $20 \mathrm{kV}$. Samples were first electrochemically polished with the same solution as the TEM specimens. As a final step, gentle ion polishing was done just before putting the sample into the microscope. Scanning was done on the square grid with the step of $100 \mathrm{~nm}$. Channel5 software was used for data processing.

Hardness across the interface formed in diffusion couples was measured with a CSM Instrument nanoindentation tester with the force of $50 \mathrm{mN}$.

\section{RESULTS AND DISCUSSION}

\section{A. General Observations}

The LM observation revealed the single-phase microstructure of the examined titanium alloys (Figure 2). The microstructure of $\alpha$-Ti alloy (Figure 2(a)) was composed of recrystallized equiaxed $\alpha$ grains - typical for hot-rolled titanium sheets. In the case of deformed $\beta$-Ti alloy (Figure 2(b)), elongated grains are observed. Such preferential orientation of the grain orientation is caused by the mechanical treatment of $\beta$ alloy, namely, by the cold rolling process.

The annealing process at $850{ }^{\circ} \mathrm{C}$ led to grain growth resulting from further static recrystallization in both coupled materials (Figure 3(a)) - especially in $\beta$-Ti. Clear $\alpha / \beta$ interface was detected between the $\alpha$-Ti and $\beta$-Ti alloys (Figure 3(b)). Its location was confirmed by the linear distribution of alloying elements using the
SEM/EDS method (Figure 4). Near the $\alpha / \beta$ interface, the diffusion-affected zones (DAZs) were easily observed. The zone in $\alpha$-Ti was marked as DAZ-1, while on the $\beta$-Ti side, it was labeled as DAZ-2. The aforementioned DAZs were characterized by different microstructure when compared with the regions located further from the $\alpha / \beta$ interface. Moreover, within the DAZ-2 (in $\beta$-Ti), formation of the pores aligned in the direction parallel to the $\alpha / \beta$ interface was observed. The pores formed the so-called Frenkel plane (Figure 3(b)). Such porosity observed in diffusion couples is related to the Kirkendall effect. ${ }^{[21]}$ It is generally accepted that cavities are formed by the precipitation of supersaturated vacancies produced by unequal diffusion currents of the Kirkendall effect-from $\beta$-Ti, containing alloying elements, to commercial pure titanium $(\alpha$-Ti) in the described case. Control of voiding in the alloys is an important practical problem of materials science. As a rule, the voiding should be suppressed since it leads to failure of final parts, e.g., microelectronic circuits. ${ }^{[25,26]}$ The voids are generated from the beginning of the diffusion process at the original interface between the $\alpha /$ $\beta$ interface, and during the diffusion process, they grow and move with the extremum of diffusion flux of the most mobile component toward the $\beta$-Ti side. The diffusion process in $\beta$-Ti can be observed; the measured element concentrations change with the measuring distance in $\beta$-Ti. Meanwhile, in $\alpha$-Ti, the Ti concentration is almost constant. This means that $\alpha-\mathrm{Ti}$ is consumed during the diffusion process (Figure 4).

\section{B. Grooving of the $\alpha / \beta$ Interface}

When two materials with different chemical composition in contact with each other are exposed to elevated temperature for a certain time, the diffusion processes will surely occur due to the difference in chemical potential. $^{[18,19]}$ The diffusion is undoubtedly connected with the mass transport in the solid state. It is widely known that the activation energy for diffusion through the grain boundaries is smaller as compared with the activation energy for volume diffusion. ${ }^{[19]}$ Therefore, the conclusion is that the mass transport through the grain boundaries will occur much earlier than that through the volume of the grain. Using SEM/BSE methods, the 

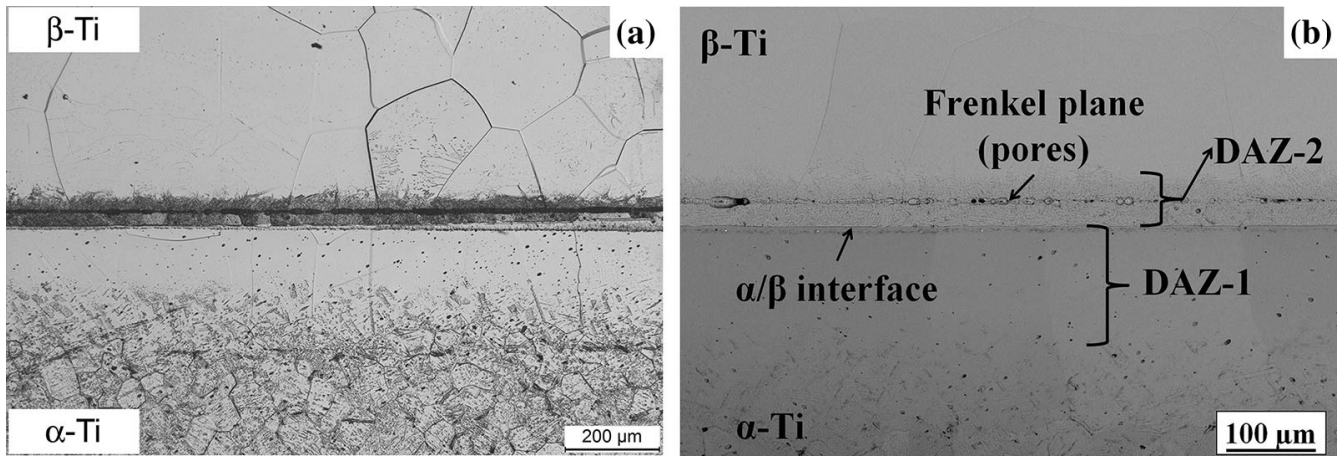

Fig. 3-Microstructure of an $\alpha$-Ti- $\beta$-Ti diffusion couple after annealing for $24 \mathrm{~h}$ at $850{ }^{\circ} \mathrm{C}$ in argon: (a) LM and (b) SEM.
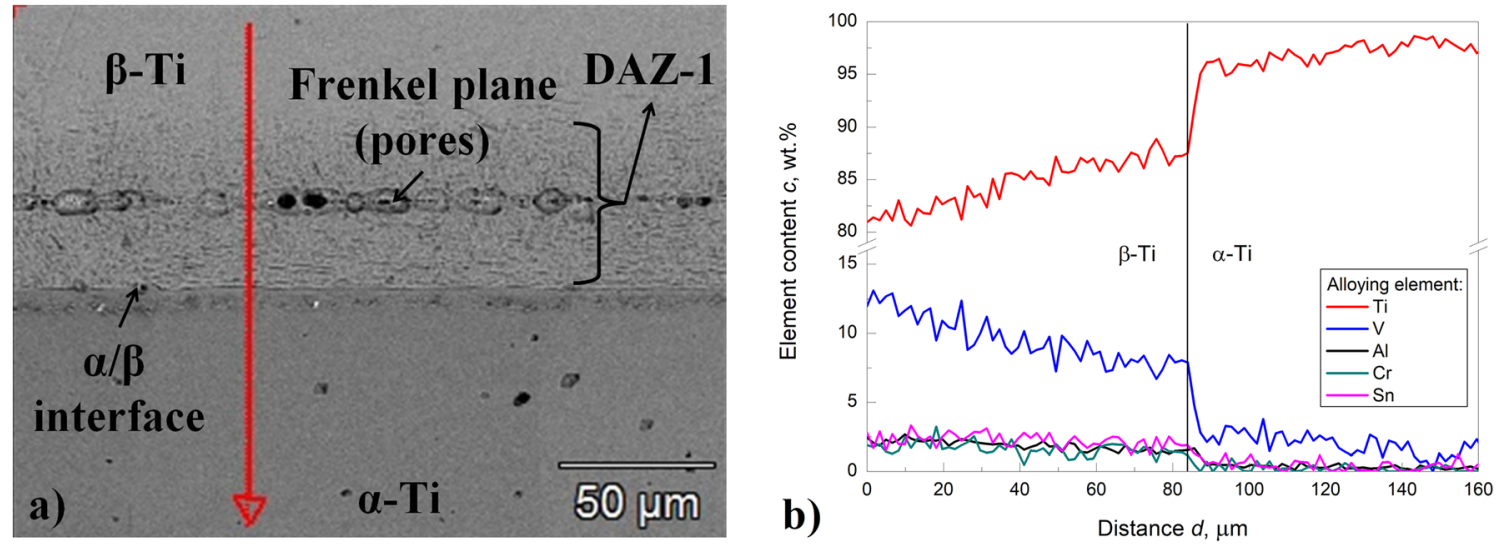

Fig. $4-$ SEM/BSE image of $(a)$ the $\alpha$-Ti- $\beta$-Ti diffusion couple and $(b)$ the element concentration profile measured by SEM/EDS along the red arrow marked in the figure.

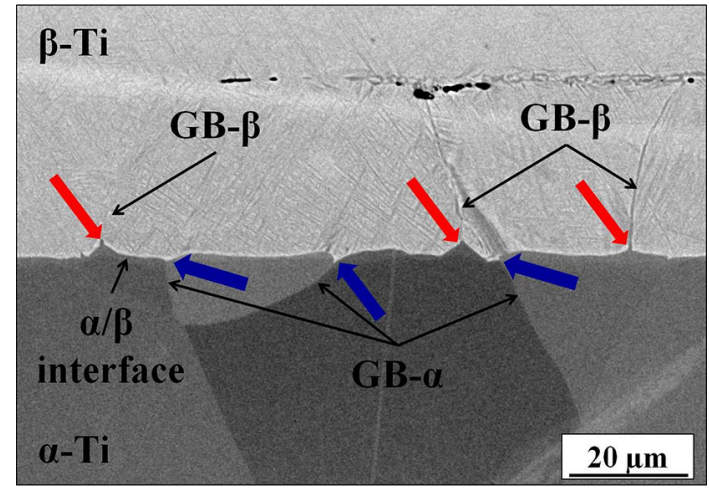

Fig. 5-SEM/BSE image showing the $\alpha / \beta$ interface revealing the so-called grooving phenomenon obtained in the $\alpha$-Ti- $\beta$-Ti diffusion couple after annealing at $850^{\circ} \mathrm{C}$ in argon atmosphere.

grooving of the $\alpha / \beta$ interface was confirmed in the examined diffusion couple (Figure 5).

The grooving phenomenon in the examined couple seems to be determined by grain boundaries in both materials, namely, in $\beta$-Ti (marked as GB- $\beta$ (Figure 5)) and $\alpha$-Ti (marked as GB- $\alpha$ (Figure 5)). It is worth mentioning that both $\alpha$ and $\beta$ phases penetrate the $\alpha / \beta$ interface (the red and blue arrows, respectively, in Figure 5). Moreover, the SEM/EDS measurement of the chemical composition on the GB- $\beta$ revealed slightly lower content of $\mathrm{Ti}$. It is commonly observed that the alloying elements tend to segregate at grain boundaries such as in the present case. Thus, due to the reactive diffusion process, the boundary between the $\alpha / \beta$ phase moves into the $\alpha$-Ti side ( $\alpha$-Ti is consumed). Due to the assumed presence of alloying elements at grain boundaries, a different diffusion flux at grain boundaries and grain volume is observed and, as a consequence, the grooving is observed.

\section{Microstructure Evolution in the DAZs}

Apart from grooving the $\alpha / \beta$ interface, microstructural changes in the DAZ-2 $(\beta$-Ti) were also observed (Figure 6(a)). As shown in a magnified view of the DAZ-2 region (Figure 6(b)), apart from pores, formation of needlelike precipitations took place (Figure 6(b)).

Martensitic $\beta \rightarrow \alpha^{\prime}\left(\alpha^{\prime \prime}\right)$ transformation in titanium alloys is usually related to the high cooling rate from the $\beta$ phase or $\alpha+\beta$ regions or to the plastic deformation (deformation-induced martensitic transformation). Even if cooling conditions after annealing favored martensite formation, it is more probable in the case of $\alpha-\mathrm{Ti}^{[3]}$ (if during annealing the temperature could be within or above $\alpha+\beta \rightarrow \beta$ transformation) than in $\beta$-Ti. The orientation of precipitates is typical for Widmanstätten microstructure: ${ }^{[3]} \alpha$ laths could be 

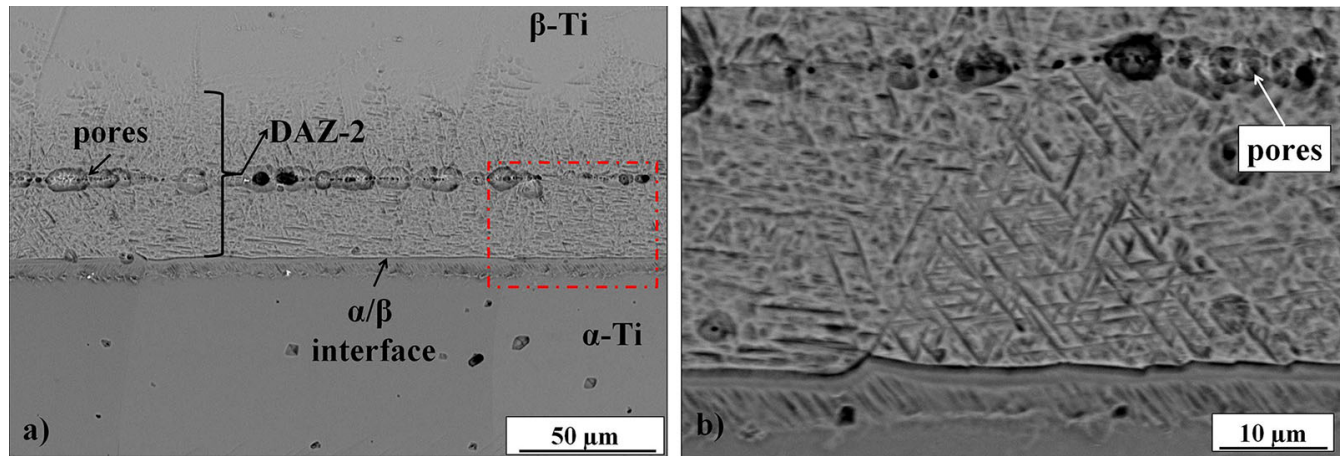

Fig. 6 - SEM/BSE images showing the microstructure of DAZ-2 in an $\alpha$-Ti- $\beta$-Ti diffusion couple after annealing at $850{ }^{\circ} \mathrm{C}$ in argon atmosphere: (a) general overview at low magnification and $(b)$ a magnified view of the region marked with a red dashed box.

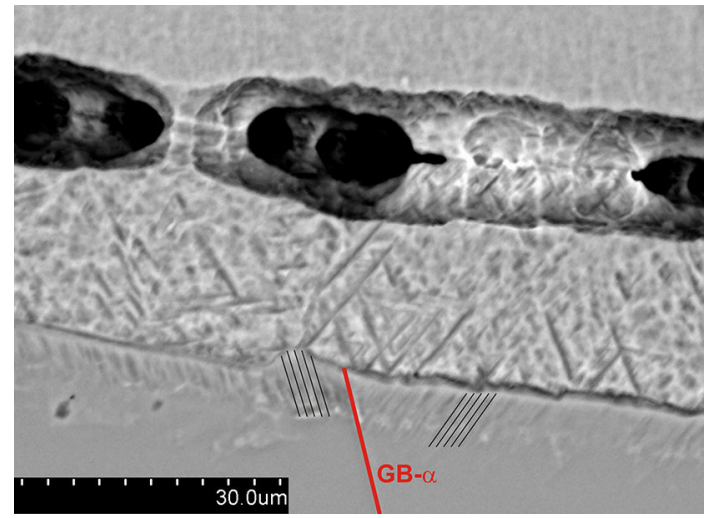

Fig. 7-Lath precipitations in the DAZs of coupled titanium alloys - Widmanstätten microstructure in $\beta$-Ti (upper layer) and parallel laths differently oriented in neighboring $\alpha$ grains (lower layer) (SEM).

formed as a result of Ti diffusion from $\alpha$-Ti alloy. In fact, parallel laths are detected also in DAZ-1 $(\alpha-\mathrm{Ti})$ (Figure 6(b)). It is interesting that their orientation is different in neighboring $\alpha$ grains (Figure 7). Lath formation in DAZs, both in $\alpha$-Ti and $\beta$-Ti, caused by diffusion of alloying elements seems to be an interesting phenomenon and needs to be explained in further investigation. Deformation-induced martensitic transformation due to the stress generated by the diffusion process or the grain growth in both dissimilar titanium alloys should also be taken into consideration.

The EBSD studies in the region of the $\alpha / \beta$ interface (marked with an arrow in Figure 8(a)) indicated that the lamellar zone was formed in near- $\beta$ alloy composed of $\alpha$ phase plates (Figures 8(b) and (c)). The phase distribution map (Figure 8(c)) indicates that the reaction front moved toward $\alpha$-Ti (the $\alpha$-Ti phase is consumed). This observation is supported by the left side of the mentioned map. No interdiffusion zone is observed in the $\alpha$-Ti side. Meanwhile, in the $\beta$-Ti side, an interdiffusion zone is observed. This interdiffusion zone is characterized by the number of differentially oriented grains (Figure 8(b)). The EBSD orientation map (Figure 8(b)) confirmed the grooving of the $\alpha / \beta$ interface by the $\alpha$
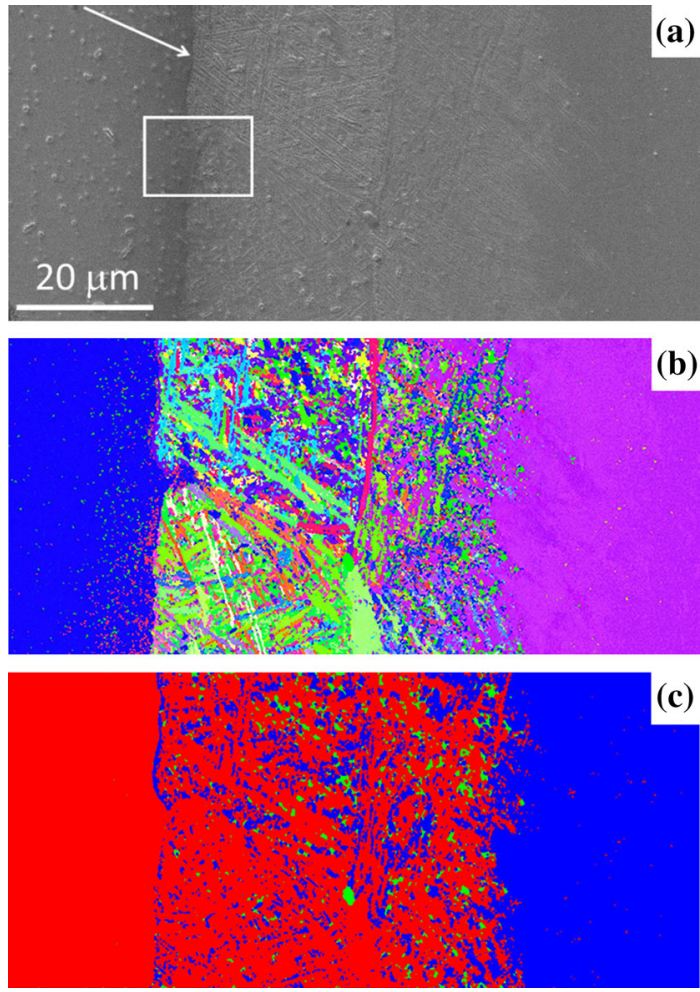

Fig. 8- SEM image of the $(a) \alpha / \beta$ interface, (b) EBSD orientation map, and $(c)$ phase distribution obtained via EBSD from the same region (red $-\alpha$, blue $-\beta)$ (Color figure online).

grain, marked with the frame in Figure 8(a), which keeps its orientation in the $\beta$ phase matrix. The region of $\alpha$ laths in the $\beta$ phase matrix, among the $\alpha / \beta$ interface, gradually vanishes in the bulk of the $\beta$ grain.

Additionally, TEM observations were carried out to learn more details about the indicated phase constituents. A low-magnification image (Figure 9(a)) revealed differently oriented needle-shaped phases. Their interior exhibits nonhomogenous amplitude contrast, which can be interpreted as the presence of an internal strain. The diffraction pattern taken from this region (Figure 9(b)) clearly indicates spots from both $\alpha$ and $\beta$ phases. 

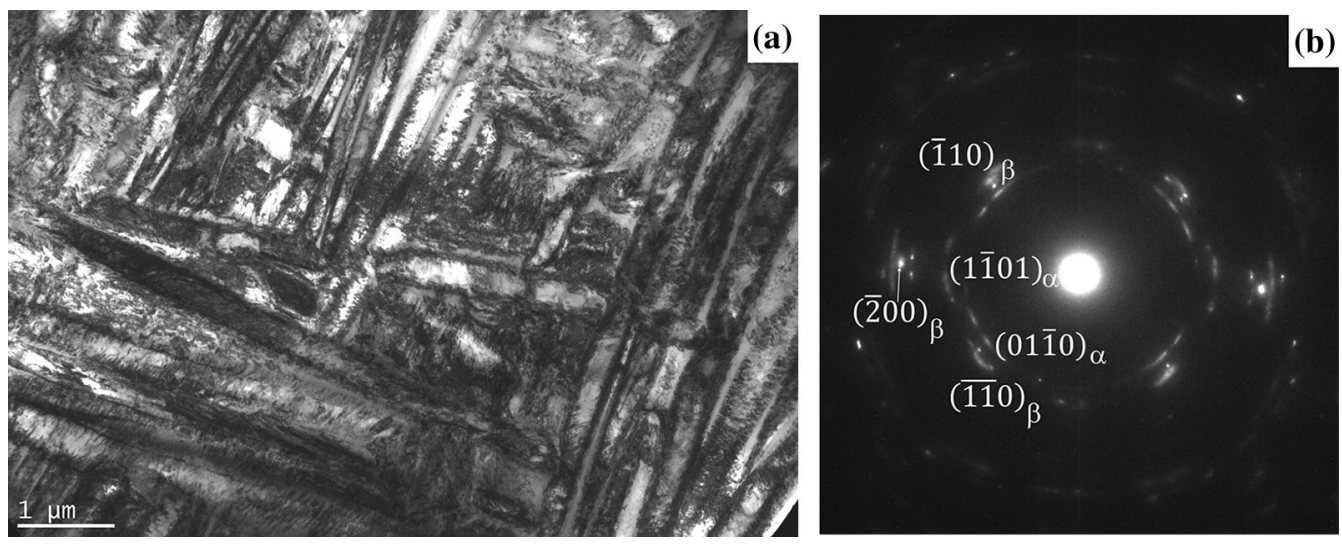

Fig. 9- (a) TEM image of the intermediate zone showing needle-shaped $\alpha$ grains and $(b)$ the diffraction pattern taken from the same region.
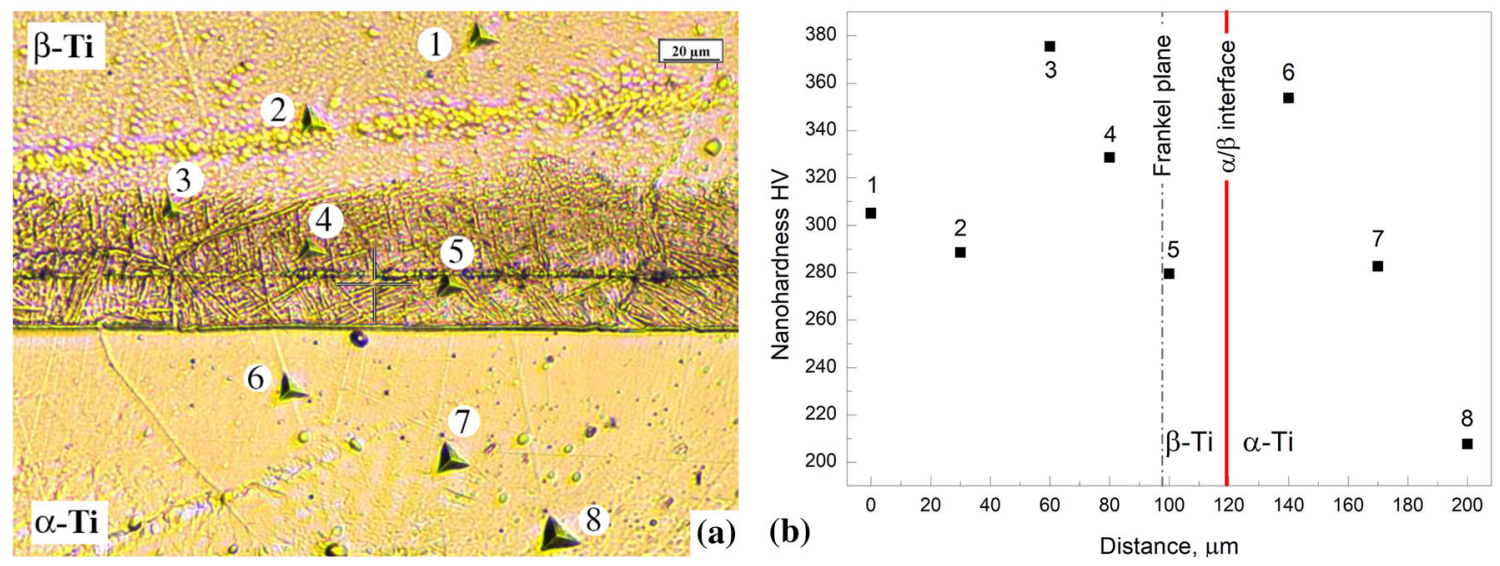

Fig. 10-Hardness across the $\alpha / \beta$ interface: $(a)$ localization of measurement points and $(b)$ hardness profile across the diffusion couple.

\section{Hardness}

The results of nanohardness measurement indicate a large difference between the hardness of examined $\alpha$-Ti and $\beta$-Ti alloys - about 210 and $300 \mathrm{HV}$, respectively (points 8 and 1 in Figure 10). Moreover, hardness in both DAZs is higher. In the case of $\beta$-Ti alloy, it results from the presence of $\alpha$ lamellae, confirmed by all microscopic methods used; the measured hardness of about $350 \mathrm{HV}$ is typical for two-phase titanium alloys having lamellar microstructure. ${ }^{[36]}$ It is worth mentioning that hardness in this region decreases toward the $\alpha / \beta$ interface (Figure 10), which can be associated with a diffusion of alloying elements to $\alpha$-Ti alloy (Figure 4(b)) and pores aligned in the Frenkel plane. The alloying elements diffusing from the $\beta$-Ti alloy harden $\alpha$-Ti alloy in its DAZ. Except for a quite thin (less than $10 \mu \mathrm{m}$ ) layer of laths (Figure 8), the microstructure of the DAZ in the $\alpha$-Ti alloy is single phase. Therefore, it can be assumed that the observed hardening was caused by a solid solution strengthening mechanism.

\section{E. Kirkendall-Frenkel Effect: Void Formation}

For a better description of the experimental results, the model predicting the void growth during the annealing time was introduced to allow extrapolation of the process. The voids are generated during the annealing process and moved with the extremum flux of the most mobile component ( $\mathrm{Ti}$ in the present case). Thus, the entire model can be simplified to solve one equation and the radii can be calculated when the vacancy diffusion coefficient and mean free path of vacancies are known. To correlate the experimental observations with the model, a measurement of the average void size was performed for the images taken by the LM, as shown in Figure 11. The average size of the voids was determined based on 45 measurements of randomly chosen locations in the cross section of the diffusion couple after the annealing process. The average diameter of the voids was measured to be $12.3 \mu \mathrm{m}$.

To calculate the void radius, the kinetic equation can be used as follows ${ }^{[25]}$ :

$$
\frac{\mathrm{d} R}{\mathrm{~d} t}=D_{\mathrm{V}}\left(N_{\mathrm{V}}-N_{\mathrm{V}}^{\mathrm{eq}}\right)\left(\frac{1}{L_{\mathrm{V}}}+\frac{1}{R}\right)
$$

where $R$ is the the void radius; $L_{\mathrm{V}}$ is the the mean free path of vacancies; $D_{\mathrm{V}}$ is the vacancy diffusion coefficient; and $N_{\mathrm{V}}$ and $N_{\mathrm{V}}^{\mathrm{eq}}$ are the vacancy molar fraction and equilibrium vacancy molar fraction $\left(N_{\mathrm{V}}^{\mathrm{eq}}=0.0002\right)$, respectively. The strength of sinks can be characterized by the mean free path of 


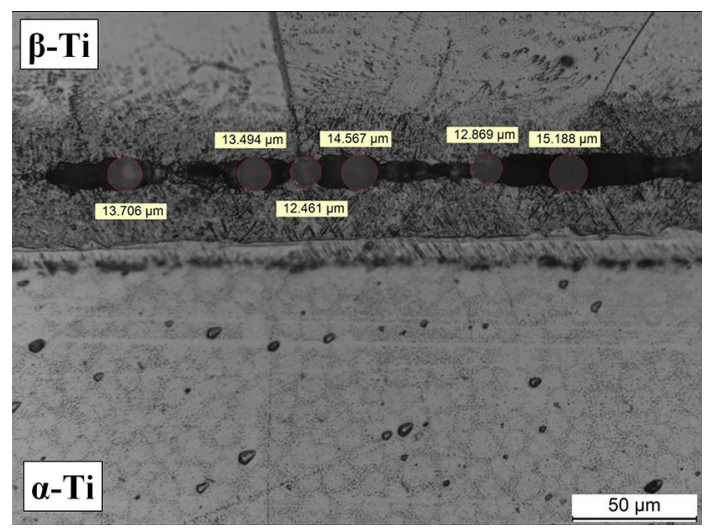

Fig. 11-Measurement of the pore radius using a LM.

vacancies $L_{\mathrm{V}} \approx \sqrt{ }\left(D_{\mathrm{V}} \tau_{\mathrm{V}}\right)$. The mean migration length describes the distance covered by a vacancy. It can be indicated that the high value of the $L_{\mathrm{V}}$ parameter results in a higher average void radius. In the case of the interdiffusion system between two components, the vacancy diffusion coefficient can be determined as ${ }^{[26]}$

$$
D_{\mathrm{V}}=\frac{D_{\mathrm{A}}^{\mathrm{I}} D_{\mathrm{B}}^{\mathrm{I}}}{N_{\mathrm{V}}\left(D_{\mathrm{A}}^{\mathrm{I}} N_{\mathrm{B}} D_{\mathrm{B}}^{\mathrm{I}} N_{\mathrm{A}}\right)}
$$

where $D_{i}^{\mathrm{I}}$ is the intrinsic diffusion coefficient of the $i$ th component.

Equation [1] was solved numerically to determine the radius of the void. It should be noted that when the initial stage for void formation is neglected, this equation can be reduced to the following form:

$$
\mathrm{d} R / \mathrm{d} t=D_{V}\left(N_{V}-N_{\mathrm{V}}^{\mathrm{eq}}\right) 1 / L_{\mathrm{V}}
$$

and solved by the simple Euler scheme:

$$
R=D_{\mathrm{V}}\left(N_{\mathrm{V}}-N_{\mathrm{V}}^{\mathrm{eq}}\right) 1 / L_{\mathrm{V}} t+R^{\min }
$$

where $R^{\min }$ is the minimum void's radius and $t$ is the time of the experiment (duration in seconds).

The data used in the calculations are as follows:

(a) the constant diffusion coefficient of titanium, $D_{\mathrm{Ti}}$ $=7.1 \mathrm{~m}^{2} \mathrm{~s}^{-1[27]}$

(b) the equilibrium vacancy concentration, $c_{\mathrm{V}}^{\mathrm{eq}}=$ $2 \times 10^{-4} \mathrm{~mol} \mathrm{~m}^{-3}$

(c) the minimum void radius, $R^{\min }=10^{-10} \mathrm{~m}$;

(d) the mean migration length, $L_{V}=10^{-7} \mathrm{~m}$;

(e) the duration of the process, $t=86,400 \mathrm{~s}$; and

(f) the constant process temperature, $T=1123 \mathrm{~K}$.

The calculated radius of voids was in good agreement with the experimentally determined values (Table I). Potentially, the model can be extended to simulate the movement of the boundary between $\alpha$ and $\beta$ phases and to calculate the phase concentration in the interdiffusion zone. However, only a simplified model was presented in this article. It seems that such an approach can be used as a criterion in the material selection for the DB process
Table I. Experimentally Determined and Calculated Values of Void Radius

\begin{tabular}{lcc}
\hline Void Radius $(\mu \mathrm{m})$ & & \\
\hline Value & Experiment & Modeling \\
\hline Average & 6.14 & 4.92 \\
Min & 4.14 & \\
Max & 8.01 & \\
\hline
\end{tabular}

of dissimilar titanium alloys. In the case of DB technology, where a compressive load is applied, some deformation mechanisms should be taken into consideration as well. ${ }^{[34,35]}$

\section{CONCLUSIONS}

Based on the results obtained in the present study, the following conclusions can be drawn.

1. As a consequence of the annealing process of the studied materials, the reaction diffusion was observed. The diffusion boundary between $\alpha / \beta$ phases is clearly visible in the SEM images.

2. The diffusion process caused changes in the alloy microstructure, especially in the interdiffusion zone.

3. The changes in the microstructure observed in the interdiffusion zone resulted in an increased microhardness.

4. The diffusion process resulted in formation of voids - the Frenkel effect. Moreover, the movement of the $\alpha / \beta$ boundary was assumed based on the growing interdiffusion zone in the $\beta$-Ti side.

5. A simple model allowing calculation of the void sizes was introduced. Correlation with the obtained experimental results showed good agreement in the void radii.

6. The grooving phenomenon, observed at the $\alpha / \beta$ interface, is related to preferential mass transport through grain boundaries.

\section{OPEN ACCESS}

This article is licensed under a Creative Commons Attribution 4.0 International License, which permits use, sharing, adaptation, distribution and reproduction in any medium or format, as long as you give appropriate credit to the original author(s) and the source, provide a link to the Creative Commons licence, and indicate if changes were made. The images or other third party material in this article are included in the article's Creative Commons licence, unless indicated otherwise in a credit line to the material. If material is not included in the article's Creative Commons licence and your intended use is not permitted by statutory 
regulation or exceeds the permitted use, you will need to obtain permission directly from the copyright holder. To view a copy of this licence, visit http://creat ivecommons.org/licenses/by/4.0/.

\section{REFERENCES}

1. F.H. Froes: Encyclopedia of Materials: Science and Technology, K.H.J. Buschow, et al., eds., Elsevier, Amsterdam, 2001, pp. 9361-64.

2. J.W. Martin: Materials for Engineering, 3rd ed., CRC Press, Boca Raton, FL, 2006.

3. M. Motyka, K. Kubiak, J. Sieniawski, and W. Ziaja: Comprehensive Materials Processing, S. Hashmi, ed., Elsevier, Amsterdam, 2014, pp. 7-36.

4. S. Zherebtsov, M. Murzinova, G. Salishchev, and S.L. Semiatin: Acta Mater., 2011, vol. 59, pp. 4138-50.

5. M. Motyka, W. Ziaja, J. Sieniawski, M. Mroczka, and M. Brylinski: Int. J. Mater. Res., 2018, vol. 109, pp. 685-93.

6. T. Seshacharyulu, S.C. Medeiros, J.T. Morgan, J.C. Malas, W.G. Frazier, and Y.V.R.K. Prasad: Scripta Mater., 1999, vol. 41, pp. $283-88$.

7. I. Weiss, F.H. Froes, D. Eylon, and G.E. Welsch: Metall. Trans. A, 1986, vol. 17A, pp. 1935-47.

8. W.W. Mullins: Trans. TMS-AIME, 1960, vol. 218, pp. 354-61.

9. S.L. Semiatin, V. Seetharaman, and I. Weiss: Mater. Sci. Eng. A, 1999, vol. 263, pp. 257-71.

10. N. Stefansson and S.L. Semiatin: Metall. Mater. Trans. A, 2003 , vol. 34A, pp. 691-98.

11. G. Sharma, R.V. Ramanujan, and G.P. Tiwari: Acta Mater., 2000, vol. 48, pp. 875-89.

12. X. Gao, W. Zeng, Y. Wang, Y. Long, S. Zhang, and Q. Wang: $J$. Alloy Compd., 2017, vol. 725, pp. 536-43.

13. S.L. Semiatin and A.L. Pilchak: Proc. 13th World Conf. on Titanium, V. Venkatesh et al., eds., John Wiley \& Sons Inc., Hoboken NJ, 2016, pp. 191-202.

14. H. Zhang and H. Wong: Acta Mater., 2002, vol. 50, pp. 1983-94.

15. D. Min and H. Wong: J. Appl. Phys., 2006, vol. 99, art. no. 023515 .

16. S. Roy and A. Suwas: Acta Mater., 2017, vol. 134, pp. 283-301.
17. Y. Chen, H. Kou, L. Cheng, Y. Zhang, Y. Yu, and Y. Lu: Materials, 2018, vol. 11, art. no. 1112.

18. A.D. Smigelskas and E.O. Kirkendall: Trans. AIME, 1947, vol. 171, pp. 130-42.

19. L.S. Darken: Trans. AIME, 1948, vol. 175, pp. 184-201.

20. M.J.H. van Dal, A.M. Gusak, C. Cserhati, A.A. Kodentsov, and F.J.J. van Loo: Phys. Rev. Lett., 2001, vol. 86, pp. 3352-55.

21. B. Wierzba: Physica A, 2014, vol. 493, pp. 29-34.

22. A. Poczekajlo, Z. Grzesik, and S. Mrowec: High Temp. Mater. Processes, 2013, vol. 33, pp. 245-51.

23. K.N. Tu: Solder Joint Technology: Materials, Properties, and Reliability, 1st ed., Springer, New York, NY, 2007.

24. K.N. Tu: Electronic Thin-Films Reliability, 1st ed., Cambridge University Press, New York, NY, 2010.

25. B. Wierzba and W. Skibinski: J. Alloy Compd., 2016, vol. 687, pp. 104-108.

26. B. Wierzba, W. Skibinski, S. Wedrychowicz, and P. Wierzba: Physica A, 2015, vol. 433, pp. 268-73.

27. F. Murdock, T.S. Lundy, and E.E. Stansbury: Acta Metall., 1964, vol. 12, pp. 1033-39.

28. D. Serafin, W.J. Nowak, and B. Wierzba: Comput. Mater. Sci., 2019, vol. 165, pp. 1-6.

29. H.-S. Lee, J.-H. Yoon, and Y.-M. Yi: Solid State Phenom., 2007, vols. 124-126, pp. 1429-32.

30. P.P. Gudipati and Y. Kosaka: Proc. 13th World Conf. on Titanium, V. Venkatesh et al., eds., John Wiley \& Sons Inc., Hoboken NJ, 2016, pp. 1631-36.

31. M.B. Nikgolov and E.S. Karakozov: Weld. Int., 1990, vol. 4, pp. 883-86.

32. J. Cope and M. Jackson: Metals, 2019, vol. 9, art. no. 654 .

33. N. Kulkarni, M. Ramulu, and D.G. Sanders: J. Manuf. Sci. Eng., 2016, vol. 138, art. no. 121010.

34. H. Margolin, A.R. Graviano, and L.S. Castleman: Metall. Trans. $A, 1977$, vol. 8A, pp. 1494-95.

35. G. Garmong, N.E. Paton, and A.S. Argon: Metall. Trans. A, 1975, vol. 6A, pp. 1271-79.

36. J. Sieniawski, W. Ziaja, K. Kubiak, and M. Motyka: Titanium Alloys-Advances in Properties Control, J. Sieniawski and W. Ziaja, eds., InTech, Rijeka, 2003, pp. 69-80.

Publisher's Note Springer Nature remains neutral with regard to jurisdictional claims in published maps and institutional affiliations. 